\title{
Teachers' Preparedness in Integrating Information and Communication Technology in Biology Classrooms in Uasin Gishu County, Kenya
}

\author{
Emily Bekyibei Bitok ${ }^{1}$ \\ ${ }^{1}$ Moi University, School of Education, P. O. Box 3900-30100, Eldoret, Kenya
}

\begin{abstract}
Increasingly, aspects of teaching and learning are being mediated through information and communication technologies, both on and off campuses, partly driven by the changes in student characteristics. Thus the delivery of secondary education is changing both in perception and implementation. However, the rate at which technology is made use of in classroom instruction is still wanting. The specific objective of the study was to examine teachers' preparedness in integrating information and communication technology in teaching and learning of Biology in secondary school in Uasin Gishu County. Descriptive survey research design was used in the study. The target population for the study was 123 secondary schools. The study used stratified sampling to select a sample of 114 teachers. Structured questionnaire and interview schedule were used to collect data. Descriptive statistics (frequencies, percentage, mean and standard deviation) were used to analyse data.. From the results of the study, teachers were averagely prepared in terms of ICT knowledge skills but lacked experience. It was thus recommended that Biology teachers need to be trained of the value of ICT because many teachers tend to perceive themselves to be technologically incompetent. Moreover, there should be on-going support for Biology teachers so that they utilize their skills on information technology in the teaching process.
\end{abstract}

Keywords: Teachers, Preparedness, Integrating Information, Communication Technology, Biology Classrooms, Uasin Gishu County, Kenya

\section{Introduction}

Improving teachers' integration of ICT in teaching has proved to be a difficult task for the education system. Research has identified several factors which can impact on the effectiveness of ICT training courses when assigned for teachers, including: individual differences among teachers, school culture and teacher interaction and follow-up and ongoing support provided to teachers when they try to implement their newly developed skills.

Individual differences among teachers: ICT professional development courses should consider the fact that teachers are widely divergent regarding their knowledge about ICT [1]. Such consideration can prevent programmes from frustrating those teachers with little or no experience in using ICT, and at the same time avoid disappointing those teachers with better ICT knowledge and skills.

School culture and teacher interaction: It is becoming apparent that the self-contained culture of schools is not aligned with the emerging aspects and skills of the knowledge-based economy such as collaboration, teamwork and communication. Increasingly, the world is more dynamic and in such an environment neither teachers nor schools can perform effectively in their traditional isolation. According to Fiszer [2], "isolation is the enemy of improvement when the practitioner must be ready to meet constantly changing student needs". Moreover, research stresses the need for teachers to share experiences with each other in order to best learn how to integrate ICT in pedagogy. As Lewis [3] puts it, schools have the potential of being learning places for teachers too, provided that the culture of schools is reshaped to facilitate this. This view is in agreement with those of Cuckle et al. [4] and Jegede et al. [5] who found teachers to be most competent in Word Processing compared to other computer applications.

Follow-Up and Ongoing Support: Pre-service education is not sufficient for teachers to be able to handle their job for the rest of their lives; rather, they require ongoing professional development and support. In the information age, where innovations are constantly introduced and change is happening rapidly, the demand for ongoing professional development is in high priority [6]. Furthermore, it might be relatively straightforward to present professional development programmes, but a greater challenge arises when teachers try to implement what they learn in real classrooms. Anderson [7] suggests that teachers might abandon new practices while they are in the early stages of implementation because of lack of assistance. This, according to Fiszer [2], is because teachers might see their newly developed skills and knowledge as "incompatible" with the everyday teaching/learning situations that they face. Therefore, Bradshaw [8] suggests that in order to maximize the return of the investment in staff development, significant resources need to be redirected to follow-up activities. In 
addition, Bradshaw (ibid) warns that without follow-up and coaching, any staff development would not impact on more than 5-10 per cent of participants' practice.

These issues, among others, need to be taken into account in order to ensure the positive impact of ICT training courses on classroom practices. As such, when introducing ICT in schools, all teachers need to: emphasize content and pedagogy not the level of sophistication with hardware and technical skills, engage students in meaningful and relevant learning, allow students to construct knowledge, bring exciting curricula into the classroom, integrate technology into the curriculum and devise alternative ways of assessing student work, adapt to a variety of student learning styles to cater for individual learning differences, and continuously expand and welcome further opportunities for teacher learning.

The ability to achieve all of the above implies that teachers must have a comfortable level of ICT skills. They must acquire the basic skills in ICT and then go on to ensure that the students in their charge can also make progress in use of ICT in an incremental way. Unless teachers are functioning at a comfortable level of ICT skills and knowledge they were unable to use ICT as a primary tool for teaching and learning across the curriculum.

Even if teachers have the ICT skills, they still need to carefully consider when, what and how to teach the ICT skills to their students [9]. Teachers may choose to use very simple or complex technologies to achieve their educational vision. Somekh and Davis [10] have demonstrated that "the use of IT can provide innovative learning experiences, but in all cases a great deal depends upon the teacher to provide the context which makes this possible". Somekh and Davis (ibid.) further indicate that: teachers need to be competent and confident users of hardware and software, but this in itself is not enough. They need also, to understand how to organize the classroom to structure learning tasks so that IT resources become a necessary and integral part of learning rather than an add-on technical aid.

Somekh and Davis (ibid) assert that unless teachers "believe in an innovation it is very unlikely that they will introduce it effectively".

For teachers to rethink and re-structure teaching and learning they must first learn enough about the relevant technologies to apply them in their professional live, and to translate them to their students as part of the integrated learning of the subject matter. Whereas in the past the role of school was thought as being to dispense information, today this role alone can no longer hold. The information explosion has changed the nature of knowing from the ability to recall information to the ability to define problems, to retrieve information selectively and to solve problems flexibly, which therefore changes the nature of learning from the need to master topics in class to the need to learn autonomously. Teachers and students now need to learn on how to learn in an ICT rich environment.

\subsection{Integrating Theory into Practice}

In many countries secondary education is undergoing transformation. Today education has to deal with significantly increased student enrolments with comparatively reduced resources, while still delivering on quality [11]. As secondary education strives to foster active and autonomous lifelong learners, it must equip students with the necessary skills and strategies that will allow them to reach this potential [12]. Increasingly, aspects of teaching and learning are being mediated through information and communication technologies, both on and off campuses, partly driven by the changes in student characteristics. Thus the delivery of secondary education is changing both in perception and implementation. Research and developments from teachers, e.g. Biology teachers, are now setting the agenda for ICT use in education in general. Thus the question today is not "if" but rather "how" technologies, current and new, can be exploited to flexibly support a more diverse student population in the $21^{\text {st }}$ century [13]. So far, ICTs have been introduced into higher education largely as a supplement to existing teaching and learning practices.

However, there is still much to be done in terms of exploiting ICTs for rich pedagogical use (enhanced teaching and learning), and for serving learners indifferent target groups [14]. While there is great advocacy for using ICT education, it is argued that teaching and learning in secondary education is unlikely to be improved simply by the application of a new technology. Learning can be enhanced when innovations take into account not only the characteristics of the technology, but also the pedagogic design, the context within which learning takes place, student characteristics, their prior experiences and their familiarity with the technologies involved.

Kirkwood and Price [15] observe that it is essential for teachers and decision-makers in higher education to develop a better understanding of the issues surrounding the use of ICT. The new circumstances for learners and learning require consideration to be given not only to the characteristics of technologies, but to: (a) the pedagogic models and processes they have to serve, and (b) the contexts within which learners engage with ICT. Thus designers and implementers of ICT need to consider access and use of ICT. They should consider the increasingly diverse backgrounds and circumstances of students, and potential students; pay attention to the 'digital divide' and use ICT where most appropriate. 
Access to ICT is rarely ideal and unrestricted and most often learners need to share computing and communication facilities with others. Therefore course design should reflect this and not be over-dependent upon ICT. Regardless of the medium being used, it is very unlikely that students will make use of the materials and activities unless they are embedded in the course pedagogy. If materials are not linked to the assessment strategy then the medium is likely to be unused and its potential will remain fallow. The medium itself is not the most important factor in any educational programme but rather how it is creatively exploited and constructively aligned (ibid).

Castro [16] further cautions on the rush to implement new technologies in developing countries. He argues that the rich countries can afford most if not all these technologies, even if they do not work well. However, the best alternatives for rich countries are not necessarily the same for less affluent countries and despite the domestic controversies surrounding the inadequacy of teachers and teacher training in OECD countries, the nature of the limitations is not the same. The shortcomings of developing countries are much more basic and the lack of preparation of teachers has a different order of magnitude. In developed countries, instructional technologies are used to take an additional step, to improve learning beyond the levels previously reached - levels already vastly superior to those reached by developing countries.

Over 30 countries in Africa still have less than one telephone line per 100 inhabitants compared to the average global ratio of 13 lines per 100 inhabitants [17]. Castro [16] therefore argues that the Internet is doomed to remain an elitist resource, available only to a small number of students and it, therefore, remains an expensive technology for developing countries. Even with falling costs over the last several decades, a computer in an American school costs less than half of the student/year cost while in developing countries it may cost ten times the student/year cost, which indicates that these technologies require resources that are particularly scarce in poor countries [16]. Furthermore, new technologies require technological resources and well-trained teachers necessary to implement the most creative use of computers in the classroom in any large scale.

What is good for developing countries is what is affordable for the masses and what compensates for the chronic scarcity of quality teachers. Castro (ibid.) proposes that instructional technologies should compensate for the shortcoming of existing teachers and for their complete absence in very poor regions. Just as rich countries have used technology to respond to their own needs, developing countries must use technology to respond to their own (but different) needs. For instance, software for computers in schools must be easy to use and non-threatening to the teachers (in the initial phases of implementation). Hence the need to be critical, selective and use a technology that best responds to local needs, rather than another one that is the latest or most sophisticated or appropriate for other (developed) countries. It is thus recommended that there should be a policy to focus initially on those institutions that have less fear of computers, such as technical and vocational schools, or those institutions created especially to use new technologies, e.g. the UK Open University. As experience in OECDs shows, the K-12 schools are the ones that most resist the use of technologies, making waste higher and results less impressive (ibid). Technology today offers many exciting alternative paths for improving education, but each of these alternatives is not equally good or appropriate for all countries.

Developed countries have used technology to make their good education even better. Therefore, when thinking of new technology solutions for education, the best solutions for less affluent countries are not necessarily to be found in the rich countries. Experiments are doomed to remain enclaves, catering to local elites but incapable of being scaled up to reach the number of people who are in dire need of better instructions. While the use of computers in classrooms is not denigrated, despite considerable efforts and after many years, developing countries need to understand that computers have not yet lived up to their educational potential, even in rich countries [16].

Developing countries need to focus on those technologies that compensate for the factors that are lacking, e.g. well-trained teachers and the resources to pay for expensive equipment. They should concentrate on those technological alternatives which, at low costs, bring to the students the imagination and creativity of a few excellent teachers, for example TV or radio. Since teachers will not be replaced by technology, much more effort should be focused on their training and selection.

Technology can only bring to the classroom the talent of other teachers and scientists which add to the skills expected from the average teacher [16].

\subsection{Problem Statement}

A review of studies on the use of technology in education has consistently found that students in technology-rich environments experience positive effects on performance in all subject areas. Despite the many advantages associated with the use of ICTs that have been documented in past literature and the numerous government efforts to investment in training and resources to integrate the use of ICT in its operations, the rate at which ICTs are used in the Kenyan classrooms is still far below expectation. For the realization of the Kenya Vision 2030, secondary school teachers need to use adequate computers in classroom teaching. In addition, the demand for ICT learning has been tremendous and the number of teachers who are trained to teach ICT cannot 
meet the demand. This failure to use ICT is itself a result of the prevailing digital and knowledge divides, and their causes are deeply embedded in the learning and performance of Biology. Therefore, there is need to energize action to bring technology into the classroom for improved Biology teaching, learning and performance. As such, the study sought to investigate integration of information and communication technology in the teaching and learning of Biology in secondary schools in Uasin Gishu County.

\subsection{Limitations of the Study}

The research into the integration of ICT in teaching Biology was relatively new and hence little information on the subject was accessed. In addition, teachers and students who are steeped in the traditional method of teaching Biology and are still groping in the dark were reluctant to volunteer information. However, the author overcame this obstacle by explaining to the teachers that the outcome of the study would result in success of the teaching and learning of Biology in the District. The study was only limited to 123 schools using ICT in teaching and learning Biology in Uasin Gishu County, where descriptive survey research design was used.

\section{Materials And Methods}

The research used a descriptive survey design. It was conducted in Uasin Gishu County which is a cosmopolitan area. The target population included all trained Biology teachers and principals/head teachers in all 123 secondary schools in Uasin Gishu County. The study sampled 30\% schools from a population of 123 giving 38 schools. From each of the secondary schools, 3 Biology teachers were selected randomly to participate in the study. The Biology teachers were randomly selected because of their knowledge in Biology and use of laboratory as well as their contact with the modern ICT while the Heads of Departments (HoDs) were selected purposively. Therefore, the total number of teachers selected from 38 schools was 114. Head teachers of every school sampled were selected purposively to participate in the study, making a sample of 38 . The total sample size of the study was therefore 152 respondents.

The instruments used to collect data for this the study were self-administered questionnaires, observation and interview schedules. Data was analyzed descriptively. Data analysis was facilitated by use of Statistical Package for Social Science (SPSS) computer program. Descriptive statistics were employed in analyzing qualitative data where frequencies and proportions were used in interpreting the respondents' perceptions of issues raised in the questionnaires so as to answer the research questions.

\section{Results And Discussion}

As shown in Table 1, the study sought to establish the level of teachers' preparedness in integrating information and communication technology in teaching Biology.

Table 1: ICT Products Mostly Used in Teaching Biology

\begin{tabular}{lll}
\hline & Frequency & Per cent \\
\hline Laptop(s) & 49 & 44.5 \\
Desktop(s) & 65 & 59.1 \\
Printed material(s) & 24 & 21.8 \\
Photocopied material(s) & 23 & 20.9 \\
Modem(s) & 21 & 19.1 \\
Digital Camera(s) & 13 & 11.8 \\
Mobile Phone(s) & 15 & 13.6 \\
\hline
\end{tabular}

As shown in Table 1 above, respondents identified the most used ICT product as follows: Laptops, 49(44.5\%); Desktops, 65(59.1\%); Printed materials, 24(21.8\%); Photocopied materials 23(20.9\%); Modems, 21(19.1\%); digital cameras, $13(11.8 \%)$, and mobile phones, $15(13.6 \%)$. This shows that the desktops are highly utilized compared to other ICT products like laptops, printed materials, photocopied materials, modems, digital cameras, while the mobile phones are the least used in teaching and learning of Biology.

\subsection{ICT Literacy in Biology}

The research sought to establish whether or not the respondents were ICT literate in Biology. The findings indicated that majority (78 out of 110) of the respondents were ICT literate whereas a minority (32 out of 110) of them were ICT illiterate. The high number of respondents who are ICT literate is attributed to the Biology curriculum which requires ICT skills in the use of equipment such as computers, laptops, modem among others.

\subsection{Means of Acquiring ICT Skills in Teaching/Learning Biology}

The research further sought to establish the various ways teachers acquired the ICT skills. The findings were as shown in Figure 1 below. 


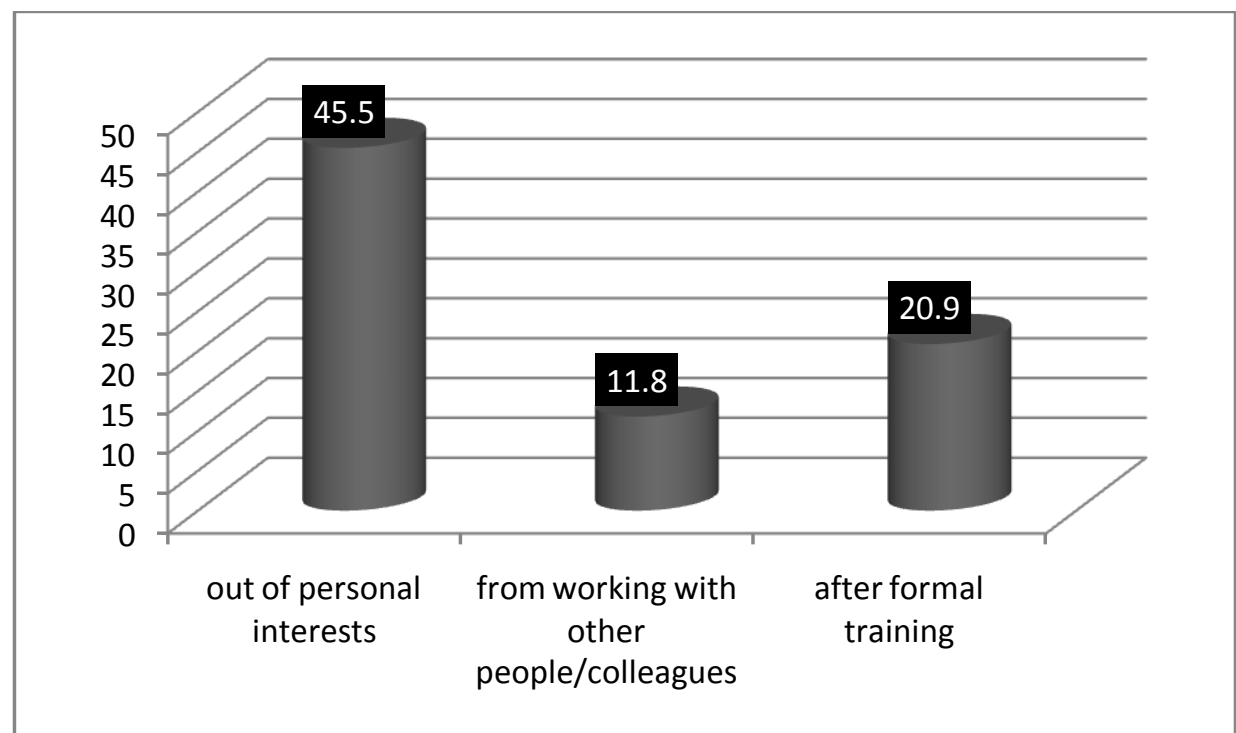

Figure 1: Means of Acquiring ICT Skills for Teaching/Learning Biology

Research findings showed that most of the teachers (45.5\%) acquired the ICT skills out of personal interest whereas some (20.9\%) acquired the ICT skills after formal training. However, this acquisition was not based on the fact that such training is a requirement in the school curriculum. The findings also showed that a significant number of teachers (11.8\%) acquired ICT skills from working with other people/colleagues.

\subsection{ICT Products used in Teaching Biology}

As shown in Table 2 below, the research sought to establish the different ICT products used in teaching Biology as shown below.

Table 2: ICT Products used in Teaching Biology

\begin{tabular}{lll}
\hline & Frequency & Per cent \\
\hline Desktop & 51 & 46.4 \\
Calculator & 36 & 32.7 \\
Photocopiers & 22 & 20 \\
Digital Camera & 11 & 10 \\
Modems & 11 & 10 \\
Mobile Phones & 16 & 14.5 \\
\hline
\end{tabular}

The study findings in Table 2 above show that out of 110 respondents who used various ICT products in the teaching of Biology, 51(46.4\%) identified the Desktop as a product they use in teaching Biology, $36(32.7 \%)$ said calculators, 22(20\%) mentioned photocopiers and 11(10\%) identified digital cameras and modems. Past research on use of mobiles in teaching/learning of Biology affirms that mobile phones are as important tools as the above ICT products commonly used in the teaching of Biology.

\subsection{Need for ICT Training in Biology}

The research sought to establish whether or not teachers who were ICT illiterate wished to train further in order to master ICT skills. The findings revealed that majority $(68 \%)$ of the teachers were interested in acquiring the ICT skills whereas a minority (32\%) of the them were not interested in acquiring ICT skills.

\subsection{Prior Training in ICT before College}

The results on teachers' ICT skills when joining the teaching profession showed that only $49 \%$ of the them acquired ICT skills before joining the teaching profession whereas $51 \%$ of the teachers did not have ICT skills before joining the teaching profession.

\subsection{Highest Qualification of ICT Training}

The study sought to investigate the highest academic qualification in ICT training among the teachers. The study findings showed that most of the teachers $(50 \%)$ were at certificate level and $12.7 \%$ were at post degree level. However, only $10 \%$ had acquired other ICT training skills such as International Computer Driving License (ICDL) and 7.3\% at diploma level. Majority of the teachers did not have sufficient knowledge and skills for the integration of ICT, while others did not have ICT knowledge and skills. 


\subsection{Frequency of using Various ICT Products in Teaching}

The research further sought to establish the frequency at which various ICT products were used by teachers in teaching. The research findings showed that the ICT products were used at varying frequencies by the Biology teachers since the acquisition of ICT skills during training defers. Most of the teachers used ICT products occasionally $(42.7 \%)$ due to the fact that they lacked of enough training in ICT knowledge and skills, while some of the teachers used them regularly $(13.6 \%)$. However, a number of teachers said they never used ICT products at all $(41.8 \%)$.

\subsection{Use of ICT in other Subjects}

The research sought to establish subjects other than Biology that used ICT products as teaching/learning tools. The findings were as illustrated in Figure 2 below.

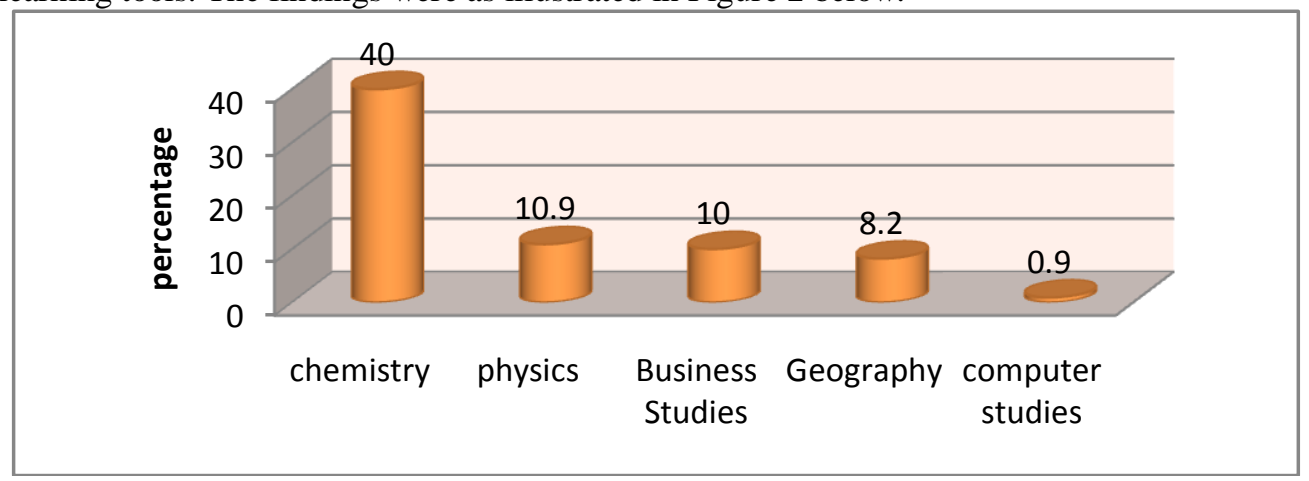

\section{Figure 2: Use of ICT in other Subjects}

The findings in Figure 2 show the use of ICT products in other subjects by teachers as teaching/learning tools was as follows: Chemistry (40\%), Physics (10.9\%), Business Studies (10\%), Geography (8.2\%) and Computer Studies (0.9\%). Chemistry had the highest percentage use of ICT products since in Chemistry there is a demand for ICT use in most of the practical experiments.

\subsection{Level of Competence in the Hardware and Software used in Teaching and Learning Biology}

The study findings in Table 3 show that teachers increasingly rely on technology to accomplish their work, capture and make sense of data and focus their efforts on measurable results in student achievement. The competence in use of various hardware and software is based on the training on use of ICT skills and knowledge

Table 3: Level of Competence in Use of Hardware and Software

\begin{tabular}{|c|c|c|c|c|c|c|}
\hline & & $\begin{array}{l}\text { Not } \\
\text { competent at } \\
\text { all }\end{array}$ & averagely & $\begin{array}{l}\text { Very } \\
\text { competent }\end{array}$ & Mean & Std. Deviation \\
\hline Word processors & Frequency & 35 & 13 & 62 & 3.36 & 1.744 \\
\hline \multirow[t]{2}{*}{ Spreadsheets } & Frequency & 37 & 34 & 39 & 2.89 & 1.644 \\
\hline & Percent & 33.6 & 30.9 & 35.5 & & \\
\hline Databases & Frequency & 49 & 24 & 37 & 2.58 & 1.541 \\
\hline $\begin{array}{l}\text { Computer-aided instruction } \\
\text { software }\end{array}$ & Percent & 42.7 & 33.6 & 23.6 & & \\
\hline \multirow[t]{2}{*}{ Presentation software } & Frequency & 57 & 21 & 32 & 2.32 & 1.465 \\
\hline & Percent & 51.8 & 19.1 & 29.1 & & \\
\hline \multirow[t]{2}{*}{ Web browsers } & Frequency & 38 & 13 & 59 & 3.08 & 1.637 \\
\hline & Percent & 34.5 & 11.8 & 53.6 & & \\
\hline \multirow[t]{2}{*}{ Use of keyboard, mouse } & Frequency & 14 & 27 & 69 & 3.6 & 1.546 \\
\hline & Percent & 12.7 & 24.5 & 62.8 & & \\
\hline \multirow{2}{*}{$\begin{array}{l}\text { Use of LCD projectors with } \\
\text { external speakers }\end{array}$} & Frequency & 33 & 24 & 53 & 3.07 & 1.733 \\
\hline & Percent & 30 & 21.8 & 48.2 & & \\
\hline
\end{tabular}

From the results shown above, the respondents were very competent in regard to the use of Word processors, 62(56.3\%): creating, opening and formatting documents, web browsers, 59(53.6\%); electronic mails, $61(55.4 \%)$; instructional films, 67(60.9\%), and use of keyboard and mouse, 69(62.8\%). The respondents were not competent at all in the use of the Spreadsheets, 37 (33.6\%), for developing marks sheets, students' 
attendance lists, time table among others; databases, 49(44.5\%), for developing students' report books; Computer-aided instruction software, 47(42.7); web browsers, 38(34.5\%), such as Google, Yahoo, Bing among others; electronic mail, 35(53.6\%), and LCD projectors with external speakers, 33(30\%). The competence in the use both software and hardware skills and knowledge was as a result of personal training and learning from colleagues.

\subsection{Skills of ICT Use in Biology Teaching}

The use of technology in teaching and learning Biology has enabled teachers to develop skills on the use of ICT hence yielding a broad array of meaningful results in Table 4.7.

Table 4: Skills of ICT Used in Biology Teaching

\begin{tabular}{|c|c|c|c|c|c|c|}
\hline & & $\begin{array}{l}\text { Not } \\
\text { skilled }\end{array}$ & Skilled & $\begin{array}{l}\text { Highly } \\
\text { Skilled }\end{array}$ & Mean & $\begin{array}{l}\text { Std. } \\
\text { Deviation }\end{array}$ \\
\hline \multirow{2}{*}{$\begin{array}{l}\text { Using virtual labs and simulations (e.g. Optics } \\
\text { Bench) for magnifying protozoa, and other cells, } \\
\text { etc. }\end{array}$} & Frequency & 46 & 12 & 51 & \multirow[t]{2}{*}{2.68} & \multirow[t]{2}{*}{1.627} \\
\hline & Percent & 41.8 & 10.9 & 47.3 & & \\
\hline \multirow{2}{*}{$\begin{array}{l}\text { Using Biology modelling software (e.g. } \\
\text { Crocodile clips) }\end{array}$} & Frequency & 33 & 35 & 42 & \multirow[t]{2}{*}{2.85} & \multirow[t]{2}{*}{1.615} \\
\hline & Percent & 30 & 31.8 & 38.2 & & \\
\hline \multirow{2}{*}{$\begin{array}{l}\text { Use of other ICT resources (e.g. Junior Insight \& } \\
\text { Sensing/sensor equipment, digital camera, E- } \\
\text { microscopes). }\end{array}$} & Frequency & 36 & 31 & 43 & \multirow[t]{2}{*}{2.91} & \multirow[t]{2}{*}{1.623} \\
\hline & Percent & 32.7 & 28.2 & 39.1 & & \\
\hline \multirow{2}{*}{$\begin{array}{l}\text { ICT skills for students with disabilities e.g. Input } \\
\text { methods include alternative keyboards, speech } \\
\text { recognition software and substitutes for a mouse. } \\
\text { Output methods include screen-readers or a } \\
\text { Braille display }\end{array}$} & Frequency & 35 & 36 & 39 & \multirow[t]{2}{*}{2.86} & \multirow[t]{2}{*}{1.594} \\
\hline & Percent & 31.8 & 32.7 & 35.5 & & \\
\hline \multirow{2}{*}{$\begin{array}{l}\text { Spreadsheets skills to be used to store, process } \\
\text { and display data, allowing time to be spent } \\
\text { analyzing rather than hand-drawing graphs. }\end{array}$} & Frequency & 54 & 27 & 29 & \multirow[t]{2}{*}{2.38} & \multirow[t]{2}{*}{1.625} \\
\hline & Percent & 49.1 & 24.5 & 26.4 & & \\
\hline \multirow{2}{*}{$\begin{array}{l}\text { Uploading of Biology learning materials in a } \\
\text { central portal by teachers where students can } \\
\text { access them }\end{array}$} & Frequency & 54 & 16 & 40 & \multirow[t]{2}{*}{2.51} & \multirow[t]{2}{*}{1.613} \\
\hline & Percent & 49.1 & 14.5 & 36.4 & & \\
\hline
\end{tabular}

Research findings shown in table 4 above indicate that teachers were not highly skilled in the use of Using virtual labs and simulations, 52(47.3\%), and were not skilled in using biological modelling software, $33(30 \%)$, use of other ICT, 36(32.7\%), (e.g. Junior insight and sensing/sensor equipment and others), use of ICT skills for students with disabilities, 35(31.8\%), (e.g. input methods such as keyboards, speech recognition software and substitutes for a mouse), use of Spreadsheets, 54(49.1\%), and uploading of Biology learning materials in a central portal by teachers where students can access them, 40(36.4\%).

\subsection{Number of Times in using ICT Materials}

In Uasin Gishu County, there is substantial evidence that technology is a vital component for the success of the entire educational enterprise. The more the teachers use ICTs the higher their competence and confidence and improved learning as well as higher academic performance. The internet, e.g. use of email, Google/Yahoo search engines, E-microscopes, smart boards, magnifying glasses, human/plant anatomy films, CDs/DVDs and electronic images and maps in presentation, are effective tools when used properly for teaching/learning on Biology as shown in Table 5 below.

Table 5: Number of Times in using ICT Material

\begin{tabular}{|c|c|c|c|c|c|c|}
\hline & & $\begin{array}{l}\text { Not at } \\
\text { all }\end{array}$ & $\begin{array}{l}\text { 1-2 times } \\
\text { per day }\end{array}$ & $\begin{array}{l}\text { 3-4 times } \\
\text { per day }\end{array}$ & $\begin{array}{l}4 \text { - } 5 \text { times } \\
\text { per day }\end{array}$ & $\begin{array}{l}\text { Above } 5 \text { times } \\
\text { per day }\end{array}$ \\
\hline \multirow{2}{*}{$\begin{array}{l}\text { Internet e.g. use of email, } \\
\text { Google/yahoo search }\end{array}$} & Frequency & 41 & 16 & 12 & 39 & 2 \\
\hline & Percent & 37.3 & 14.5 & 10.9 & 35.5 & 1.8 \\
\hline \multirow{3}{*}{$\begin{array}{l}\text { Microscopes e.g. E - } \\
\text { Microscopes }\end{array}$} & Frequency & 110 & & & & \\
\hline & percent & 100 & & & & \\
\hline & Frequency & 92 & 15 & 3 & & \\
\hline \multirow{2}{*}{ Use of smart boards } & & & & & & \\
\hline & Percent & 83.6 & 13.6 & 2.7 & & \\
\hline \multirow[t]{2}{*}{ Magnifying glasses } & Frequency & 42 & 34 & 17 & 3 & 14 \\
\hline & Percent & 38.2 & 30.9 & 15.5 & 2.7 & 12.7 \\
\hline Human/plants anatomy films. & Frequency & 81 & 5 & 13 & 0 & 11 \\
\hline Videos & Percent & 73.6 & 4.5 & 11.8 & 0 & 10 \\
\hline Distribution of Biology content & Frequency & 94 & 13 & 3 & 0 & 0 \\
\hline
\end{tabular}


Teachers' Preparedness in Integrating Information and Communication Technology in....

\begin{tabular}{llllllll}
\hline through CDs/DVDs & Percent & 85.5 & 11.8 & 2.7 & 0 & 0 \\
Use of Electronic images and & Frequency & 92 & 6 & 4 & 8 & 0 \\
$\begin{array}{l}\text { Maps for presentation in } \\
\text { Biology class }\end{array}$ & Percent & 83.6 & 5.5 & 3.6 & 7.3 & 0 \\
\hline
\end{tabular}

The research findings in Table 5 show that most respondents, 39(35.5\%) used the internet 4-5 times per day whereas $12(10.9 \%)$ used the internet 3-4 times a day. Moreover, $41(37.3 \%)$ did not use the internet at all. All the respondents, $110(100 \%)$ did not use the E-Microscopes at all in learning/teaching of Biology. The use of smart boards was not common among the respondents thus $92(83.6 \%)$ of the respondents did not use it at all whereas only $15(13.6 \%)$ used it $1-2$ times a day. The magnifying glass was used 1-2 times by $34(30.9 \%)$ of the respondents and 3-4 times by $17(15.5 \%)$ of the respondents and above 5 times a day by $14(12.7 \%)$ of the respondents.

In relation to the use of human/plants anatomy films, $81(73.6 \%)$ of the respondents did not use it at all whereas $13(11.8 \%)$ of the respondents used it 3-4 times a day and 5(4.5\%) used it 1-2 times a day. In addition, the distribution of Biology content through CDs/DVDs was not common among the respondents since 94(85.5\%) of them did not use it at all whereas only $13(11.8 \%)$ used it 1-2 times per day. In conclusion, the use of electronic images and maps for presentation in Biology class was not common among the respondents.

The study findings reveal that an attempt to improve teachers' integration will impact positively on the teaching of Biology using information and communication technology. It is therefore important for teachers to share experiences with each other in order to best learn how to integrate ICT since schools have the potential to be learning places for teachers too, providing that the culture of schools is reshaped to facilitate this as asserted by Lewis [3]. From the research findings, is evident that the ongoing support for ICT integration in teaching and learning Biology makes it possible for teachers to upgrade their knowledge and skills thus teachers require ongoing professional development and support.

The findings also concur with the views of Fiszer [2] that teachers might see their newly developed skills and knowledge as "incompatible" with the everyday teaching/learning situations that they face each day. It is therefore necessary to maximize the return of the investment in staff development by having followed up activities so that teachers use the skills and knowledge in ICT in the teaching process, as asserted by Bradshaw [8]. This way teacher will be able to emphasize on the content and engage students in meaningful and relevant learning and integrate technology into the curriculum thus expanding and welcoming further opportunities for teacher learning.

\section{Conclusion And Recommendations}

The study provides evidence to show that teachers' preparedness in integrating information and communication technology has a significant effect on the learning/teaching of Biology. The findings show that the school culture and ongoing support for ICT integration in teaching and learning makes it possible for teachers to upgrade their knowledge and skills on information and communication technology in the teaching of Biology.

The study findings also show that most of the teachers occasionally use the information and communication technology. Therefore, teachers need to be sensitized on the value of ICT because many teachers tend to perceive themselves to be technologically incompetent. There should also be training for teachers who are not ICT competent so that they are able to use the various ICT tools used in the learning of Biology.

From the study findings, it is recommended that there should be ongoing support for teachers so that they utilize their skills on information technology in the teaching process. There should also be a follow-up so that there is efficient use of ICT tools by teachers using the knowledge and skills gained in ICT.

\section{References}

[1]. Galanouli, D., Murphy, C., \& Gardner, J. (2004). Teachers perceptions of the effectiveness of ICT-competence training. Computers \& Education, 43, 63-79.

[2]. Fiszer, E. P. (2004). How Teachers Learn Best: an ongoing professional development model. Maryland: ScarecrowEducation.

[3]. Lewis, A. C. (1998). A New Consensus Emerges on the Characteristics of Good Professional Development. In R. Tovey (Ed.), Harvard Education Letter Focus series 4: Professional Development (pp. 12-16). Cambridge, MA: Gutman Library.

[4]. Cuckle, P., Clarke, S., AND Jenkins, I. (2000). Students' information and communications technology skills and their use during teacher training. Journal of Information Technology for Teacher Education, 9(1), 9-22.

[5]. Jegede, P.O. (2009). Issues in Informing Science and Information Technology Volume 6, 2009 Assessment of Nigerian Teacher Educators' ICT Training Obafemi Awolowo University.

[6]. World Bank. (2002). Lifelong Learning in the Global Knowledge Economy: Challenges for Developing Countries. Washington DC: World Bank.

[7]. Anderson, J. (1997). Information Technology Options for Educational Management: Challenges and Responses. Managing Educational Realities in Asia and the Pacific: A Report of South East Asia and Pacific Region Educational Administrators' and Managers' Symposium (Vol. II), SEAPREAMS, Darwin. 
[8]. Bradshaw, L. K. (2002). Technology for Teaching and Learning: Strategies for Staff Development and Followup Support. Journal of Technology and Teacher Education, 10(1), 131-150.

[9]. Teacher Training Agency, (1998) The Use of ICT in subject teaching, - Expected Outcomes of the New Opportunities Fund ICT training initiative for teachers in England, Wales and Northern Ireland. Teacher Training Agency: London.

[10]. Somekh B. and Davis N.E. (Eds.) (1997) Using IT effectively in teaching and learning: studies in pre-service and in-service teacher education. Routledge: London and New York.

[11]. Harvey, Lee \& Knight, Peter T. (1996). Transforming Higher Education. Open University Press, Bristol.

[12]. Candy, P. (1998). Knowledge navigators and lifelong learners: producine graduates for the information society, in: C. Rust (ED.) Improving student learning: improving students as learners. (Oxford, Oxford Centre for Staff and learning Development, 26, 19-28.

[13]. Moon, Bob \& Dladla, Nhlanganiso. (2002). Challenging the assumptions about teacher education and training in Sub-Saharan Africa: a new role for open learning and ICT. Presented to the Pan-Commonwealth Forum on Open Learning, International Convention Centre, Durban, South Africa July 29th 2002.http://www.open.ac.uk/deep/Public/web/publications/pdfs/NDladlaBMoon2002-PCF.pdf

[14]. Collis, B. \& Van Der Wende, M. (Eds). (2002). Models of technology and change in higher education, Center for Higher Education policy Studies, University of Twente, the Netherlands. In Kirkwood, Adrian \& Price, Linda. (2005). Learners and learning in the twenty-first century: what do we know about students' attitudes towards and experiences of information and communication technologies that will help us design courses? Studies in higher Education, Vol. 30, no.3, June 2005, 257-274.

[15]. Kirkwood, Adrian \& Price, Linda. (2005). Learners and learning in the twenty-first century: what do we know about students' attitudes towards and experiences of information and communication technologies that will help us design courses? Studies in higher Education, Vol. 30, no.3, June 2005, 257-274.

[16]. Castro, Claudio de Moura. (2003). Are new technologies better technologies? For whom? Chapter 2, 39-54. In UNESCO. (2003). Adapting technology for school improvement: a global perspective. http://unesdoc.unesco.org/images/0013/001361/136149e.pdf

[17]. Mannisto, Laura; Kelly, Tim \& Petrazzini, Ben. (1997). Internet and Global Information Infrastructure in Africa. ITU. http://www.itu.int/ITUD/ict/papers/witwatersrand/tam_tam.pdf 